\title{
Design Analysis of Pump as Turbine for a Coastal Region of Nigeria
}

\author{
Obriki Mudiaga, Anthony Kpegele Le-ol, Barinyima Nkoi
}

\begin{abstract}
This research details the design analysis process of a $100 \mathrm{~kW}$ Pump as Turbine (PAT) micro hydro system for Sangama Community in the Niger Delta Region of Nigeria. In order to achieve this, governing equations of fluid flow in pumps and pipes were applied to determine suitable design parameters of the system components, and also to select an appropriate pump configuration. A design software, PAT+, was built in $\mathrm{C \#}$ to help perform the design computations involved, although the software can be applied to PAT design for any expected power rating and desired system efficiency. From the results obtained, it was seen that a single stage pump of $3600 \mathrm{rpm}(60 \mathrm{rev} / \mathrm{s})$ operating at an efficiency of $79.6 \%$ and a head of 107.68 metres was suitable to generate the expected power. Parameters were varied and plots generated to show the effect of some parameters on others. It was deduced that the system head is inversely proportional to the flow rate and for higher power outputs, higher system heads would be needed, although expected design output of a PAT should not exceed $100 \mathrm{~kW}$.
\end{abstract}

Index Terms-Specific Speed; Micro-Hydropower; Pumpas-Turbine; System Head; Pump Efficiency.

\section{INTRODUCTION}

Energy plays an important role in almost all aspects of human and commercial activities. Everything runs on one form of energy or the other. Every sector of every economy in the world is dependent on at least one form of energy. For developing nations, it is a vital input for economic development. Fossil fuel has been reliable for years, but due to the negative effects on the environment, alternative energy sources have been developed. These alternatives are known as renewable energy. There are different forms of renewable energy, one of which is hydropower (power from water). Hydropower is non-polluting and effective means of energy generation.

In 2016, the World Energy Council published that hydropower is the leading source of renewable energy in the world, providing $71 \%$ of all generated renewable electric power. With an installed capacity of over 1,064 gigaWatts (GW), it contributed $16.4 \%$ of global electricity from both renewable and non-renewable sources [1]. These figures are set to grow as hydropower potential is very huge. In Africa, only an estimated $9 \%$ of its hydropower potential has been developed till date [1]. According to World Energy Council [1], when a hydroelectric plant is designed to produce a maximum of $100 \mathrm{~kW}$ (kilowatts) and a minimum of $5 \mathrm{~kW}$, it

Published on March 12, 2019

The Authors are with the Mechanical Engineering Department, Rivers University, Port Harcourt, Rivers State, Nigeria. mudiinventsfinancials@gmail.com; le-ol.anthony@ust.edu.ng; nkoi.barinyima@ust.edu.ng is referred to as a micro hydropower plant. Micro hydro power plants are generally used in the provision of electric power for rural villages with no access to the electricity grid. This, often applies to developing countries. The design of micro hydro power plants can be done as per household or at the village level depending on the expected power output and intent of the designer. As far back as 1995, an estimated capacity of $28 \mathrm{GW}$, which was equivalent to $115 \mathrm{TWh}$ of electricity was generated by micro-hydro power plants. About $80 \%$ of this $28 \mathrm{GW}$ was in the developed nations, with $20 \%$ in developing nations [1]. These figures have greatly changed, as developing nation across the world are investing in micro hydropower plants. One of the micro hydropower technologies with increasing interest is the reversal of a pump to function as a turbine, known in short as a pump as turbine (PAT) system. A pump as turbine system reverses the operation of a pump, making it function as a turbine with the aim of generating or recovering energy.

However, in Nigeria, the pump as turbine technology has not attracted much interest. In a society like Nigeria, with huge power demands and poor power supply, pump as energy systems could be a solution to many households and rural communities. PAT systems are relatively cheap to run and maintain. The initial cost of installation may be high but it would be a more reliable solution in comparison to petrol generators, which is the number one source of backup power in Nigeria.

Pumps are physically and hydraulically similar to turbines. Turbine converts pressure energy and kinetic energy of a working fluid into mechanical energy of its runner whereas pump converts the mechanical energy of its impeller into pressure energy and kinetic energy of a working fluid, which in many cases is water. If a pump is operated in reverse mode, it can function as a turbine. Using a Pump as a turbine is cheaper and easier to maintain than conventional turbine systems

The earliest application of water in generating power was first conceived in china during the Han dynasty between 202 $\mathrm{BC}$ and 9AD [2]. The mechanism of operation involved vertical-set water wheels powering trip hammers which were used to break ore, pound and hull grain and in papermaking.

The first half of the 19th century birthed new and important development in hydropower technology. French engineer, Benoit Fourneyron, in 1827, developed a turbine capable of generating about 6 horsepower which is seen as the earliest version of the Fourneyron reaction turbine. In 1849, the first modern water turbine was developed by British American engineer James Francis. The Francis turbine remains the most widely used water turbine in the world today. In the 1870s, the Pelton wheel (an impulse 
water turbine) was developed by the American inventor Lester Allan Pelton and was patented in 1880 [3]. Austrian Professor Viktor Kaplan developed the Kaplan turbine (a propeller-type turbine with adjustable blades) in 1913. The world's first hydroelectric project was used to power a single lamp in the Cragside country house in Northumberland, England, in 1878.

Four years later, the first plant to serve a system of private and commercial customers was commissioned in Wisconsin, USA. Within the next decades hundreds of hydropower plants were in operation. In North America, hydropower plants were installed at Grand Rapids, Michngan in 1880, Ottawa, Ontano in 1881, Dolgeville, New York in 1881 and Niagara Falls, New York in 1881. These power plants were primarily used to supply mills and light some local building.

By the 20th century, hydropower technology was spreading round the globe, with Germany producing the first three-phase hydroelectric system in 1891, and Australia launching the first publicly owned plant in the Southern Hemisphere in 1895. In 1895, the world's largest hydroelectric development of the time, the Edward Dean Adams power plant, was created at Niagara Falls [4]. A hydroelectric station was built near Taipei on the Xindran creek in 1905 with an installed capacity of 500KW. The development was quickly followed by the first station in mainland China, the Shilongba plant in the Yunnan province, which was built in 1910 and put into operation in 1912. Shilongba had an installed capacity of $480 \mathrm{KW}$ upon completion and is still in operation today with an installed capacity of 6MW [4].

The USA and Canada were the leading force with regards hydropower engineering in the first half of 20th century. The Hoover Dam on the Colorado river at $1345 \mathrm{MW}$ became the world's largest hydroelectric plant in 1936 until it was surpassed in 1942 by the Grand Coulee Dam with a then capacity of 1974MW. Large hydropower plants were developed in Canada, USSR, and cation amen ca from 1960s through to the 1980s.

With respect to the equipment cost, operating costs and pay outs for the different sizes of Reverse Osmosis systems, carried out experiments to determine the economics of Hydropower Recovery Turbines (HPRT) and they deduced that the Head vs Capacity and BHP vs Capacity relationships are an essential criterion for selection and operation of HPRTs [5]. It was also discovered that using centrifugal pumps as HPRT increased plant efficiency by reducing power consumption per unit volume of the water produced.

A method for determining the main design parameters of the system which can be used to install pump as turbine systems across irrigation structures was developed in 1985 by [6]. The available low-head energy in irrigation channels/canals can be used to drive a turbine connected to a pump which can be used to lift water for irrigation or domestic purpose. Their work led to the conclusion that offdesign performance of the system can be controlled to achieve maximum pump flow all year. Also, they advised that Pump as Turbines should be considered where lowheads are available.

Reference [7] described the use of PAT as good alternative to utilize the excess available energy in natural falls, irrigation systems, water supply, rain systems which would be lost in normal conditions. Analysis of steady state conditions was done based on some chosen parameters to prove that pumps can be used in industrial process and production of renewable energy. It was concluded that whatever the type of motor or alternator that was adopted, PAT is an unorthodox solution to energy production.

Reference [8] investigated the hydraulic system response (under steady and transient state) to analyze the results between a pressure reducing value (PRV) and PAT (also working as PRV) in drinking pipe system [8]. Thus, PAT can be used both as PRV and to generate power using the energy stored in pressurized water. It was deduced that PAT can be better than PRV in some cased but in some cases, the use of both (PAT and PRV) was preferable.

Investigation into the method of recovery of energy from water distribution system by coupling and replacing PRVs and PATs was conducted by [9]. An optimization was done using PIKAIA (Genetic algorithm support by NITSOL algorithm) as a hydraulic solver. Their research led to the conclusion that PRV can be replaced or integrated with PAT and such replacement or integration minimizes loss in water distribution network.

A $97 \mathrm{KW}$ micro-hydro system was designed by [10] for the Roman Bay sea farm in Gansbaai, Western Cape province of South Africa. The requirements of the sea farm included a large amount of seawater for the various growing cycles of the farm. Water was pumped in holding tanks which were then gravity fed to the various processes of the micro-hydro system.

Sangama is a little coastal community located in the Niger Delta region of Nigeria. It has a population of less than 2000 people. It is surrounded on all sides by rivers. Materials and Methods

\section{A. Methods}

Analytical methods were used in this research. The governing equations for pump flow in normal usage as well as flow when the pump is reversed were analyzed to determine several parameters for a good design. From the results of these calculations, pump configurations that will suit the design case was proposed.

A software, PAT+ was used to perform all calculations and simulations required in this research. Also, relevant plots were obtained using the PAT + software. PAT + is a software that was developed by Obriki Mudiaga for design of Pump as Turbine Systems. It is written in C\#..

\section{1) Design Parameters}

There are three basic parameters that determine the design of the Pump as Turbine System. These are the overall head of the system, the flow rate and the expected power output.

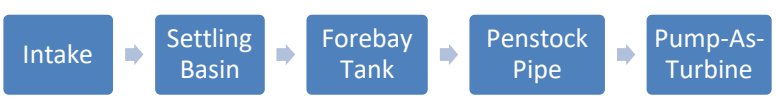

Fig. 1. Circle of Operation of the PAT System 


\section{2) Hydrodynamic Analysis of a Pump working as a}

\section{Turbine}

When a pump runs as a turbine, the high-pressure fluid enters the machine and then leaves after the conversion of the energy has occurred within the impeller. Since the flow direction and the rotational speed are reverse, the velocity triangles of both modes change. This can be seen in Fig. 2 . Although only the shaft rotation and flow direction are opposite in pump and turbine modes, their velocity triangles are different. The efficiencies of pump mode and turbine mode differ.

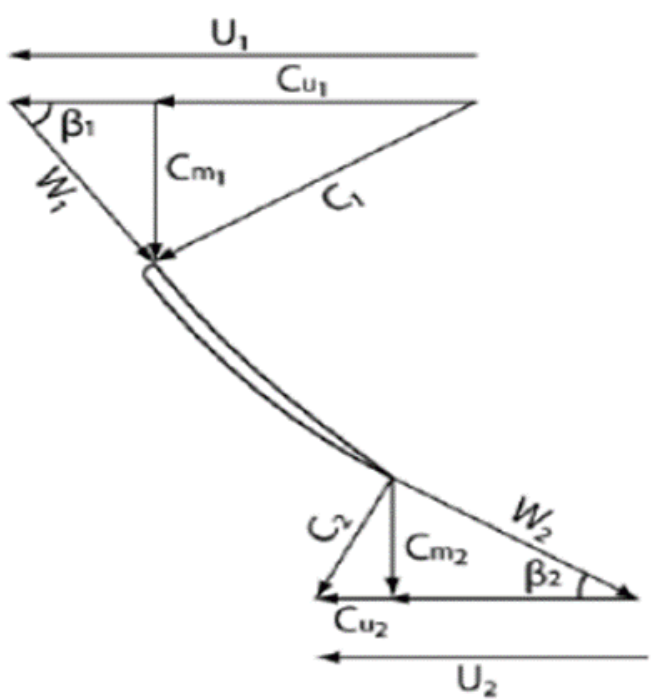

Fig. 2. Velocity Triangle of Pump as Turbine.

In Fig. 2, W1 is the relative velocity at the inlet, U1 is the peripheral velocity at the inlet, $\mathrm{Cu} 1$ is the tangential velocity at the inlet, $\mathrm{C} 1$ is the absolute velocity at the inlet, $\mathrm{Cm} 1$ is the inlet flow velocity, $\beta 1$ is the inlet blade angle and $\mathrm{U} 2$, $\mathrm{Cu} 2, \mathrm{C} 2, \mathrm{Cm} 2$ and $\beta 2$ are corresponding values at the outlet side of the pump.

Pump-turbine characteristics are normally expressed in terms of three dimensionless properties, the dimensionless flow coefficient, the dimensionless head coefficient and the dimensionless power coefficient. These are expressed in (1), (2) and (3):

$$
\begin{aligned}
& Q_{D}=\frac{Q}{N D^{3}} \\
& H_{D}=\frac{g H}{N^{2} D^{2}} \\
& P_{D}=\frac{P}{\rho N^{3} D^{5}}
\end{aligned}
$$

where $\mathrm{Q}_{\mathrm{D}}$ is the dimensionless flow coefficient, $\mathrm{Q}$ is flowrate of fluid through the system, $\mathrm{N}$ is specific speed, $\mathrm{D}$ is inlet diameter, $\mathrm{H}_{\mathrm{D}}$ is the dimensionless head coefficient, $\mathrm{g}$ is acceleration due to gravity, $H$ is the system head, $P_{D}$ is the dimensionless power coefficient, $\rho$ is the fluid density and $\mathrm{P}$ is the power generated/input into the system.

Wang [11] proposed correlations to get the dimensionless turbine flow relative to pump flow, and the dimensionless turbine head relative to pump head. These are expressed in (4) and (5) respectively.

$$
\begin{aligned}
& \vartheta_{t}=1.99^{0.5} \vartheta+2^{-6.48} \\
& \varphi_{t}=1.5^{0.5} \varphi+1.34^{0.5}
\end{aligned}
$$

where $\vartheta_{\mathrm{t}}$ is the dimensionless flow parameter of turbine mode, $\vartheta$ is the dimensionless flow parameter of pump mode, $\varphi_{\mathrm{t}}$ is the dimensionless head parameter of turbine mode and $\varphi$ is the dimensionless head parameter of pump mode.

The charts in Figs 3 and 4 show the dimensionless flow parameters at BEP (Best Efficiency Point) of turbine mode versus pump mode for values from 1 metre to 100 metres and $1 \mathrm{~m} 3 / \mathrm{s}$ to $100 \mathrm{~m} 3 / \mathrm{s}$.

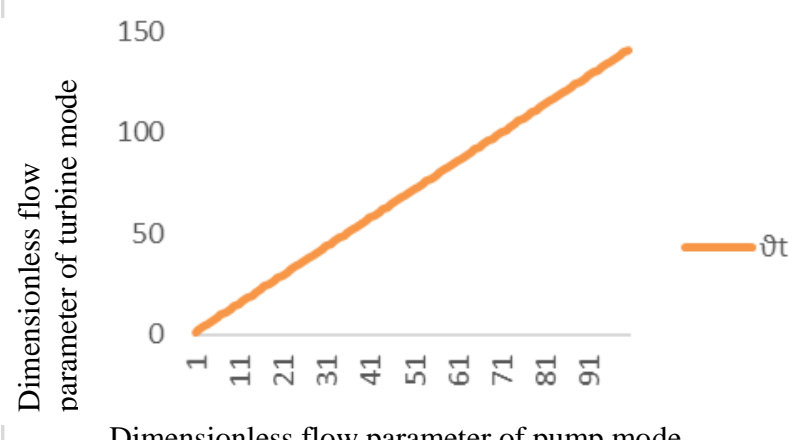

Dimensionless flow parameter of pump mode

Fig. 3. Dimensionless flow parameter of turbine mode versus pump mode.

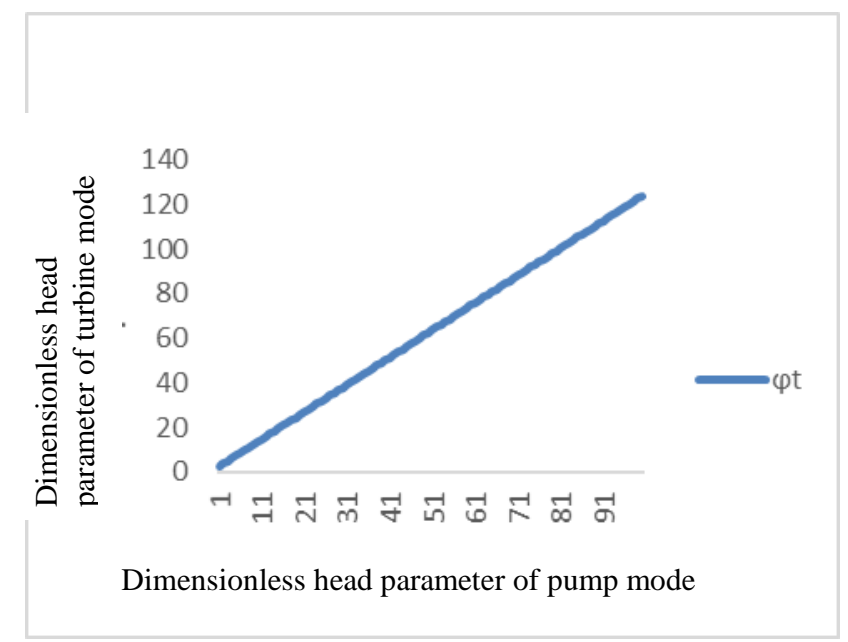

Fig. 4. Dimensionless head parameter of turbine mode versus pump mode.

From the plots above, the following can be deduced between normal operation of a pump and operating a pump in turbine mode:

a. The head needed for the same power input/output is significantly higher in turbine mode

b. The flow rate needed for the same power is higher in turbine mode

c. For the same head and flow rate, the efficiency of a pump when operating in turbine mode is lower than when it's operating normally in its pump mode.

\section{3) Design Equations}

Each pump has certain values for maximum efficiency, voltage, frequency, rpm, discharge diameter, power rating, maximum permissible flow rate and head. These can usually be found on the label or on a document from the 
manufacturer. When the pump is operating under these conditions, it is operating at its maximum efficiency and is said to be at the best efficiency point (BEP). The PAT site has a specific head and volumetric flow which will be calculated based on the expected power output. These values are different from the BEP values for the pump when it is operated as a turbine.

At best efficiency point (BEP), we assume that there is no rotational speed. Also, for optimal operation and stability, the value of the inlet angle is usually chosen between 13 degrees and 22 degrees, and peripheral velocity I the range of $35 \mathrm{~m} / \mathrm{s}$ to $42 \mathrm{~m} / \mathrm{s}$. We also have a desired efficiency of $75 \%$, frequency of $50 \mathrm{~Hz}$ and power rating of $100 \mathrm{~kW}$. The following equations are applied to determine the pump configuration and efficiency when operating in turbine mode.

Design equations for each component are given below:

\section{a) The Settling Basin}

The first thing in designing a settling basin is to choose a suitable width for the basin. From previous researches, it is recommended to choose a basin with between two to five times the width of the intake channel [12]. Next, the length of the basin can be calculated with (6):

$$
L_{b}=\frac{2 Q}{W_{i} V_{f}}
$$

where $L_{b}$ is the Length of Settling Basin, $Q$ is the flow rate, $\mathrm{W}_{\mathrm{i}}$ is the width of the intake channel, $\mathrm{V}_{\mathrm{f}}$ is the fall velocity.

Next, we need to calculate an acceptable value for the depth of the settling basin $\left(\mathrm{D}_{\mathrm{S}}\right)$. In order to do that, we must first calculate the silt load $\left(\mathrm{S}_{\mathrm{L}}\right)$ and volume of silt stored in the basin $\left(\mathrm{V}_{\mathrm{S}}\right)$ using the following equations:

$$
\mathrm{S}_{\mathrm{L}}=\mathrm{QTC}_{\mathrm{s}}
$$

where $\mathrm{Q}$ is the flowrate, $\mathrm{T}$ is the Silt Emptying Frequency in seconds, taken as 43,200 s and $\mathrm{C}_{\mathrm{s}}$ is the concentration of incoming silt in $\mathrm{kg} / \mathrm{m}^{3}$

$$
V_{s}=\frac{s_{L}}{s_{d} P a_{f}}
$$

where Vs is the volume of silt,

$\mathrm{Sd}=$ Density of silt coming into settling basin, taken as $2.6 \mathrm{~kg} / \mathrm{m} 3$

Paf $=$ Packing factor of silt, which is normally taken as $50 \%$ $(0.5)$.

The depth of the settling basin,

$$
D_{s}=\frac{V_{s}}{L_{b} W}
$$

\section{b) Forebay Tank}

The width, height and depth of the forebay tank are identical to that of the settling basin. However, submergence head (Hs) must be calculated. The submergence head is the depth of water above the crown of the penstock pipe. If it is too small, air may enter into the penstock pipe, causing unwanted flow pattern in the penstock pipe and eventual damage of the penstock pipe. The basic rule while calculating the submergence head is given in (10).

$$
H_{s} \geq \frac{1.5 \mathrm{~V}^{2}}{2 g}
$$

where Hs is the submergence head, $\mathrm{V}$ is the flow velocity in the Penstock Pipe and $g$ is acceleration due to gravity.

\section{c) Penstock}

The most important factor when designing the penstock is the type of material used. From reviewed literatures, uPVC (unplasticized polyvinyl chloride) is chosen as a good material for the design. This is because it reduces friction loss when compared to other materials, it is relatively cheap, and it handles pressure, weight and corrosion very well. The internal diameter of the pipe can be derived from (12).

$$
D=\sqrt{\frac{4 Q}{\pi V}}
$$

where $\mathrm{D}$ is the pipe internal diameter, $\mathrm{Q}$ is the flowrate and $\mathrm{V}$ is the flow velocity in the penstock.

It is also important to calculate the head loss in the pipe. The total loss is expressed as

$\mathrm{Hl}_{\mathrm{oss}}=\mathrm{H}_{\text {min }}+\mathrm{H}_{\text {maj }}$

where Hmin is the minor head losses and Hmaj = major head losses.

$$
H_{m a j}=\frac{k L V^{2}}{2 g D}
$$

where $\mathrm{k}$ is friction factor for $\mathrm{uPVC}$ material (dimensionless), $\mathrm{L}$ is the penstock pipe length, $\mathrm{V}$ is the flow velocity in the penstock pipe, $\mathrm{D}$ is diameter of the penstock pipe, $\mathrm{g}$ is acceleration due to gravity and Hmaj is the major head losses.

$$
H_{\min }=\frac{x V^{2}}{2 g}
$$

where $\mathrm{H}_{\min }$ is the minor head losses, $x$ is the total pipe shape geometry coefficient (dimensionless), $\mathrm{V}$ is the flow velocity in the pipe and $\mathrm{g}$ is acceleration due to gravity.

\section{d) Pump as Turbine}

In calculating the design parameters of the pump, the total head of the pump needed to deliver the expected power has to be known.

Total Head,

$$
\mathrm{H}=\mathrm{H}_{\mathrm{eff}}+\mathrm{H}_{\mathrm{loss}}
$$

where $\mathrm{H}_{\mathrm{eff}}$ is the effective system head.

The inlet diameter of the pump is taken as the diameter of the penstock pipe.

$$
\mathrm{D}_{\text {pump }}=\mathrm{D}
$$

where $\mathrm{D}$ is the diameter of the penstock pipe.

The flow rate of water in the pump, 


$$
\mathrm{Q}=\mathrm{AV}
$$

where $\mathrm{A}$ is the cross-sectional area of penstock pipe in $\mathrm{m} 2$.

The efficiency of a pump as turbine is expressed as

$\eta=\frac{\text { output Power }}{\text { Input } \text { Work }}=\frac{P}{W}$

Input Work $=$ Fluid work on the impeller

$\mathrm{W}_{\text {in }}=\rho g \mathrm{QH}$

where Win is the work input

Substituting (19) into (18) yields

$$
\eta=\frac{P}{\rho g Q H}
$$

where $\eta$ is the efficiency of the pump operating as a turbine.

The RPM rating of the pump,

$$
\mathrm{N}=\frac{60 U_{2}}{\pi D s}
$$

where Ds is the shaft diameter of pump, $U$ is the Peripheral Speed of shaft, N is the RPM rating of the pump.

Turbine Specific Speed of the pump when operating as turbine is given as

$$
\mathrm{N}_{\mathrm{sp}}=\frac{N Q^{\frac{1}{2}}}{H^{\frac{3}{4}}}
$$

According to Derakhshan \& Nourbakhsh [12], Specific speed of pump when operating in turbine mode,

$$
\mathrm{Nst}=0.3705 \mathrm{Nsp}-5.083
$$

From Grover Correlations, Pump Efficiency,

$$
\eta_{p}=\frac{\text { Specific Speed of Turbine }, N_{s t}}{\text { Specific Speed of Pump }, N_{S}}
$$

Making Ns subject of the formula yields

$$
\mathrm{N}_{\mathrm{s}}=\frac{N_{s t}}{\eta_{p}}
$$

\section{B. Design Algorithm}

Step 1: Set the expected output power

Step 2: Set parameters of the intake weir based on the chosen case study

Step 3: Set parameters of the silt based on chosen case study. If no silt parameters data, use standard values

Step 4: Calculate for Design parameters of the Settling basin

Step 5: Calculate the design parameters of the forebay tank. Most times, the design parameters of the forebay tank are identical to those of the settling basin

Step 6: Calculate the Submergence head

Step 7: Calculate the required diameter of the penstock pipe

Step 8: Obtain the head losses in the penstock pipe
Step 9: Calculate the pump parameters, that is the operational head, the specific speed, the power input to shaft and the rotational speed of the pump

Step 10: Based on results obtained, select type of pump and configuration.

\section{About PAT+}

PAT+ is a pump-as-turbine design and simulation software. It is built on the Microsoft .Net Framework with the C\# Language. It can be used for design and simulation of PAT systems for various case studies.

\section{RESULTS AND DISCUSSION}

The design equations were applied, and with the required inputs, results were obtained. The design inputs, results and discussions are presented in this section.

\section{A. Design Input Parameters}

Several design inputs are needed for computation of the results of the system. Some of these inputs, e.g. Design power and width of intake channel, were set from the design study chosen while some were obtained from recommended fail-safe design parameters. These include the recommended silt parameters for design of PAT systems which are the silt emptying frequency, silt concentration, density of silt and packing factor, and the fall velocity of water in the system,

\begin{tabular}{|c|c|c|c|c|}
\hline S/N & Parameter & Nomenclature & Unit & Value \\
\hline 1. & Output Power & $\mathrm{P}$ & $\mathrm{kW}$ & 100 \\
\hline 2. & Width of Intake Channel & Wi & $\mathrm{m}$ & 0.34 \\
\hline 3. & Fall Velocity & $V_{f}$ & $\mathrm{~m} / \mathrm{s}$ & 0.03 \\
\hline 4. & Silt Emptying Frequency & $\mathrm{T}$ & $\mathrm{s}$ & 43200 \\
\hline 5. & Silt Concentration & $\mathrm{C}_{\mathrm{s}}$ & $\mathrm{kg} / \mathrm{m}^{3}$ & 0.5 \\
\hline 6. & Density of Silt & $\mathrm{Sd}$ & $\mathrm{kg} / \mathrm{m}^{3}$ & 2.6 \\
\hline 7. & Packing factor & $\mathrm{Pa}_{\mathrm{f}}$ & - & 0.5 \\
\hline 8. & $\begin{array}{l}\text { Recommended Velocity of } \\
\text { water in Penstock Pipe }\end{array}$ & $\mathrm{V}$ & $\mathrm{m} / \mathrm{s}$ & 3 \\
\hline 9. & Wave Velocity of water & $\mathrm{a}$ & $\mathrm{m} / \mathrm{s}$ & 1400 \\
\hline 10. & Friction Factor & $\mathrm{k}$ & - & 150 \\
\hline 11. & $\begin{array}{l}\text { Pipe Shape Geometry } \\
\text { Coefficient }\end{array}$ & $\mathrm{x}$ & - & 1 \\
\hline 12. & Fluid (Water) Density & $\rho$ & $\mathrm{kg} / \mathrm{m}^{3}$ & 1000 \\
\hline 13. & Fluid (Water) Density & Q & $\mathrm{m}^{3} / \mathrm{s}$ & 0.1 \\
\hline 14. & Shaft Diameter of Pump & $\mathrm{D}_{\mathrm{s}}$ & $\mathrm{m}$ & 0.2 \\
\hline
\end{tabular}
the design flow rate and expected diameter of output shaft. Constants used in the design include acceleration due to gravity, density of water, wave velocity of water, friction factor and pipe shape geometry coefficient. These inputs and their corresponding values are shown in Table I.

TABLE I: DESIGN INPUT PARAMETERS

\section{B. Design Calculations and Results}

The design inputs were applied into the design equations and results for each component of the Pump as Turbine System were obtained. The calculations are shown below:

\section{1) The Settling Basin}

Width of Settling Basin, $\mathrm{W}=4$ x $0.34 \mathrm{~m}=1.36 \mathrm{~m}$

Length of Basin, $\mathrm{L}_{b}=\frac{2 \times 0.1}{1.36 \times 0.03}=4.9 \mathrm{~m}$

Silt Load, SL $=1 \times 43200 \times 0.5=2160 \mathrm{~g}=2.16 \mathrm{~kg}$ 
Volume of Silt, Vs $=\frac{2.16}{2.6 \times 0.5}=1.66 \mathrm{~m}^{3}$

Depth of Settling Basin, Ds $=\frac{1.66}{4.9 \times 1.36}=0.25 \mathrm{~m}$

\section{2) Forebay Tank}

Width of Tank, $\mathrm{W}_{\mathrm{T}}=$ Width of Setting Basin $=1.36 \mathrm{~m}$

Length of Tank, $\mathrm{L}_{\mathrm{T}}=$ Length of Settling Basin $=4.9 \mathrm{~m}$

Depth of Tank, $\mathrm{D}_{\mathrm{T}}=$ Depth of Settling Basin $=0.25 \mathrm{~m}$

Submergence Head, $\mathrm{H}_{\mathrm{s}} \geq \frac{1.5 * 3^{2}}{2 * 9.8} \geq 0.69 \mathrm{~m}$

\section{3) Penstock}

Pipe Diameter, $D=\sqrt{\frac{4 \times 0.1}{3.142 \times 3}}=0.65 \mathrm{~m}$

Major Head Losses, $\mathrm{H}_{\text {maj }}=\frac{150 \times 0.0049 \times 3^{2}}{2 \times 9.8 \times 0.65}=5.18 \mathrm{~m}$

Minor Head Losses, $\mathrm{H}_{\min }=\frac{0.1 \times 3^{2}}{2 \times 9.8}=0.46 \mathrm{~m}$

Total Head Losses, $\mathrm{H}_{\text {losses }}=5.18 \mathrm{~m}+0.46 \mathrm{~m}=5.64 \mathrm{~m}$

\section{4) Pump-As-Turbine}

Effective head, $\mathrm{H}_{\mathrm{eff}}=\frac{100000}{1000 \times 9.8 \times 0.1}=102.04 \mathrm{~m}$

Total System Head, 102.04m + 5.64m = 107.68m

Inlet Diameter of Pump $=$ Diameter of Penstock Pipe $=$ $0.65 \mathrm{~m}$

\section{Peripheral Velocity of Pump, $\mathrm{U}=30 \mathrm{~m} / \mathrm{s}$}

RPM Rating of Pump, $\mathrm{N}=\frac{60 \times 30}{3.142 \times 0.2}=2864.4 \mathrm{revs} / \mathrm{min}=$ $47.7 \mathrm{rev} / \mathrm{s}$

Specific Speed of Pump, Np $=\frac{477 \times 1^{\frac{1}{2}}}{19.23^{\frac{3}{4}}}=25$

$\mathrm{RPM}$ rating of chosen pump, $\mathrm{N}_{\text {chosen }}=3600 \mathrm{rpm}=60 \mathrm{rev} / \mathrm{s}$

Efficiency of the Pump $=\frac{2864.4}{3600}=79.6 \%$

\section{Results from the Developed Software, PAT+}

PAT+ is written in C\#. It is windows based and straight forward to use. The user provides the design inputs, clicks on Design and the outputs and corresponding graphs are plotted.

Using the PAT+ software, the following results were obtained:

TABLE II: RESULTS OBTAINED FROM PAT+

\begin{tabular}{|c|c|c|c|}
\hline S/N & Parameter & Unit & Value \\
\hline 1. & Width of Basin & $\mathrm{m}$ & 1.36 \\
\hline 2. & Length of & $\mathrm{m}$ & 4.9 \\
\hline
\end{tabular}

\begin{tabular}{|c|c|c|c|c|}
\hline & Basin & & & \\
\hline 3. & Depth of Basin & $\mathrm{m}$ & & 0.25 \\
\hline 4. & $\begin{array}{l}\text { Width of } \\
\text { Forebay tank }\end{array}$ & $\mathrm{m}$ & & 1.36 \\
\hline 5. & $\begin{array}{l}\text { Length of } \\
\text { Forebay tank }\end{array}$ & $\mathrm{m}$ & & 4.9 \\
\hline 6. & $\begin{array}{l}\text { Depth of } \\
\text { Forebay Tank }\end{array}$ & $\mathrm{m}$ & & 0.25 \\
\hline 7. & $\begin{array}{l}\text { Penstock Pipe } \\
\text { Diameter }\end{array}$ & $\mathrm{m}$ & & 0.65 \\
\hline 8. & $\begin{array}{l}\text { Pump Design } \\
\text { head }\end{array}$ & $\mathrm{m}$ & & 107.68 \\
\hline 9. & $\begin{array}{l}\text { RPM of Pump } \\
\text { in rev/s }\end{array}$ & $\mathrm{rev} / \mathrm{s}$ & & 47.7 \\
\hline 10 & $\begin{array}{l}\text { Specific Speed of } \\
\text { Pump } \\
\text { RPM of Selected }\end{array}$ & - & 25 & \\
\hline 11. & $\begin{array}{l}\text { Pump } \\
\text { Pump Efficiency }\end{array}$ & $\mathrm{rev} / \mathrm{s}$ & 60 & \\
\hline 12. & & $\%$ & 79.6 & \\
\hline
\end{tabular}

\section{Pump Selection and Design Configuration Based on Results}

To deliver the required power of $100 \mathrm{~kW}$, a single stage centrifugal pump would be the best choice. It would operate at a total system head of 107.68 metres and has a specific speed of 25, which falls within specific speed range of centrifugal pumps. Another reason a centrifugal pump was chosen is because the flow of the system is not very large. If it was very large, an axial pump would have been a better option. Also, the pump chosen has a rotational speed of $60 \mathrm{rev} / \mathrm{sec}$ as this is slightly higher than the minimum design speed of 47.7rev/s obtained from the calculation.

\section{E. Power Output variation with Head}

The design head was varied severally to see how it affects the power output of the system. The variation is shown in the Fig. 5. As seen in the graph, there is a positive linear relationship between the power output and the design head. The higher the design head, the more power the system outputs.

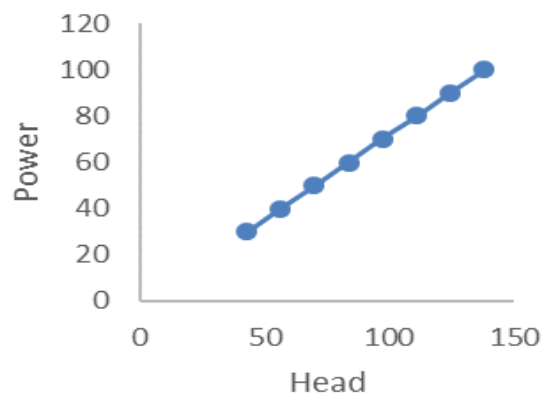

Fig. 5. Power Variation with Head.

\section{F. Head Variation with Flow Rate}

The total system head varies inversely with the design flow rate. The higher the flow rate, the lower the design head and vice versa. The design inputs were varied and the corresponding outputs gotten. These were used to plot Fig. 6. 


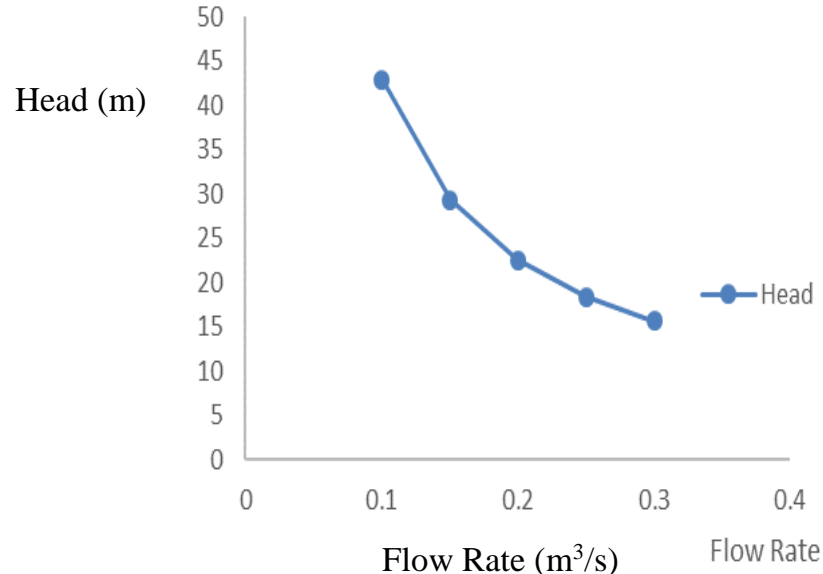

Fig. 6. Variation of Total system head with Flow Rate

\section{CONCLUSION}

A design analysis for a Pump as Turbine System to deliver $100 \mathrm{~kW}$ of power was carried out for Sangama Community in the Niger Delta Region of Nigeria. The following conclusions were drawn:

i. A single stage centrifugal pump of $60 \mathrm{rev} / \mathrm{s}$, with an operational head of 107.86 metres was best suited for the expected power output.

ii. The pump would operate at an efficiency of $79.6 \%$.

iii. The system head varied inversely with the flow rate

iv. For higher power outputs, higher system heads would be required. This is because the power output is directly proportional to the head.

To improve the design, the following is recommended:

i. Variable Guide vanes should be designed for the pump. This will enable the pump handle varying flow speeds

ii. Cost analysis should be done for design of Pump-asTurbine Systems in Nigeria

\section{ACKNOWLEDGMENT}

We wish to thank the Lord, God Almighty for his grace and mercies He has shown from the beginning of this research up to now. We are also grateful to the Head of Department, Mechanical Engineering, Rivers State University, Prof. J. I. Sodiki for his understanding, guidance, constructive criticisms, patience and encouragement. Thanks also go to all the lecturers and staff of the Department of Mechanical Engineering for their inputs from the beginning of the research up till now. Special thanks go to our families and friends, who gave us priceless support and encouragement.

\section{REFERENCES}

[1] World Energy Council. World Energy Resources, Hydropower. 2016.

[2] International Finance Corporation, "Hydroelectriv Power: A Guide for Developers and Investors", pp/ 6-16. 2016

[3] Umanand K., Singh P., Tiwat A.C, "Suitability of Archimedes Screws for Micro Hydro Power Generation in India", International Journal of Thermal Technologies, Vol. 6, No. 3, 2018

[4] International Hydropower Association, 2018 hydropower status report: Sector trends and Insights, 2016

[5] Raja, Waheed \& W. Piazza, Robert. (1981). Reverse running centrifugal pumps as hydraulic power recovery turbines for seawater reverse osmosis systems. Desalination. 38. 123-134. 10.1016/S0011-9164(00)86054-3.

[6] R. Mankbadi, R \& Mikhail, S. (1985). A Study of a TurbineGenerator System for Low-Head Hydropower. 10.1115/85-GT-141.

[7] Ramos, H., \& Borga, A. (1999). Pumps as turbines: an unconventional solution to energy production. Urban Water; Volume 1, Issue 3, 261-263.

[8] Ramos, H., Covas, D., Araujo, L., \& Melo, M. (2005). Available energy assessment in water supply systems. Proceedings of the Congress-International Association for Hydraulic Research, (pp. 250-251).

[9] Giugni, M., Fontana, N., \& Portolano, D. (2009). Energy saving policy in water distribution networks. International conference on renewable energies and power quality, 2009

[10] Teuteberg, B. H. (2010). "Design of a Pump-As-Turbine for an Abalone Farm. Final Report for Mechanical Project 878, Department of Mechanical and Mechatronic Engineering, Stellenbosch University, 2010.

[11] Pandey R., Performance analysis of modified pump used as turbinell, M.Tech. Dissertation; AHEC, IIT Roorkee, 2008

[12] Derakhshan, S., \& Nourbakhsh, A. (2008). Experimental study of characteristic curves of centrifugal pumps working as turbines in different specific speeds. Experimental Thermal and Fluid Science, $32(3)$. 